\title{
COMPARISON OF MANUAL VACUUM ASPIRATION UNDER LOCAL ANESTHESIA AND SUBLINGUAL MISOPROSTOL IN MANAGEMENT OF INCOMPLETE MISCARRIAGE IN GMC TEACHING HOSPITAL, NEPAL
}

Malati Tripathi ${ }^{1}$, Kripa Sherchan ${ }^{2}$

\section{ABSTRACT}

\section{INTRODUCTION}

To compare the efficacy of using sublingual misoprostol and manual vacuum aspiration under local anesthesia in the treatment of spontaneous incomplete miscarriage (up to 6 to 12 weeks of pregnancy).

\section{MATERIAL AND METHODS}

This is a prospective study performed in Gandaki Medical College (GMC) Teaching Hospital, Pokhara on 150 patients with spontaneous incomplete miscarriage between 6 to 12 weeks of pregnancy. Patients were divided into two groups: group (I) patient who took $400 \mu \mathrm{g}$ misoprostol every four hourly for maximum of three doses, group (II) patient who underwent manual vacuum aspiration (MVA) under local anesthesia. Only 68 patients in group I and 64 patients in group II completed their follow up and were included in this study.

\section{RESULTS}

The success rate of MVA under local anesthesia was $100 \%$ and misoprostol was $67.7 \%$ (p-value $<0.05$ ). Both misoprostol and MVA under local anesthesia are effective for treatment of incomplete miscarriage.

\section{CONCLUSION}

Although, success rate of MVA under local anesthesia is more than misoprostol, both MVA and misoprostol can be used, as an effective method of uterine evacuation in incomplete abortion of $<12$ weeks.

KEYWORDS Local Anesthesia, Manual Vacuum Aspiration, Miscarriage, Misoprostol

1. Associate Professor, Department of Obstetrics \& Gynaecology, Gandaki Medical College, Nepal

2. Lecturer, Department of Obstetrics \& Gynaecology, Gandaki Medical College, Nepal

\author{
For Correspondence \\ Dr. Malati Tripathi \\ Associate Professor \\ Department of Obsterics and Gyanaecology \\ Gandaki Medical College, Pokhara, Nepal \\ Email: drmalatitripathigme@gmail.com
}




\section{INTRODUCTION}

Early pregnancy loss or miscarriage is a common gynaecological problem faced by women of reproductive age groups. ${ }^{1}$ When some part of product of conception is not expelled and a part of it is left inside the uterine cavity, it is called incomplete miscarriage. Approximately, 11-15\% of pregnancies end in spontaneously first trimester miscarriage. ${ }^{2,3,4,5}$ According to the World Health Organization (WHO), 87,000 maternal deaths due to incomplete abortion are recorded yearly in developing countries. ${ }^{2,3}$ Incomplete abortion in first trimester could be managed through medical and surgical interventions. Medical intervention that is used is misoprostol. Misoprostol is cheap, stable at room temperature, long half-life and easily administered via sublingual, oral, per vaginal or per rectal route. Medical management of incomplete miscarriage using misoprostol is particularly helpful in places with limited human resources and is effective with few side effects. It is also safe and acceptable among women who are not willing for invasive procedures. ${ }^{6}$ Surgical management has been the standard care worldwide for many years in the past. Manual vacuum aspiration is a most common surgical method to complete evacuation and to prevent infection and hemorrhage. Therefore, the aim of this study was to compare effectiveness of sublingual misoprostol versus manual vacuum aspiration under local anesthesia in the treatment of spontaneous incomplete miscarriage.

\section{MATERIAL AND METHODS}

This is a prospective study conducted in department of Obstetrics and Gynaecology in GMC, Pokhara, Nepal over 2 years from $15^{\text {th }}$ Feb 2015 to $14^{\text {th }}$ Feb 2017. The present study was cleared by the ethical committee of GMC. This study included 150 women between 6 to 12 weeks of pregnancy with spontaneous incomplete miscarriage, confirmed by ultrasound.

Patients who were hemodynamically unstable, diabetic, had cardiac disease, Rh negative, septic abortion, fever, bronchial asthma or known hypersensitivity to misoprostol were excluded from the study. All patients signed a written informed consent before recruitment into the study. The eligible patients were divided into two groups according to patient choice. Group (I) received misoprostol tablet $400 \mu \mathrm{g}$ sublingually every four hourly for a maximum of three doses Group (II) underwent vaginal manual vacuum aspiration under local anesthesia. All patients were followed up for the first 24 hours for abdominal pain, presence of excessive vaginal bleeding, vital signs and any other complications. All patients were advised that they could return to hospital at any time if complication arises orif advice was required. The data was entered manually on Microsoft Excel (2000; Microsoft Corporation, Redmond, WA, USA), checked for possible data entry errors. The statistical significant difference among groups was determined by the Chi square test.

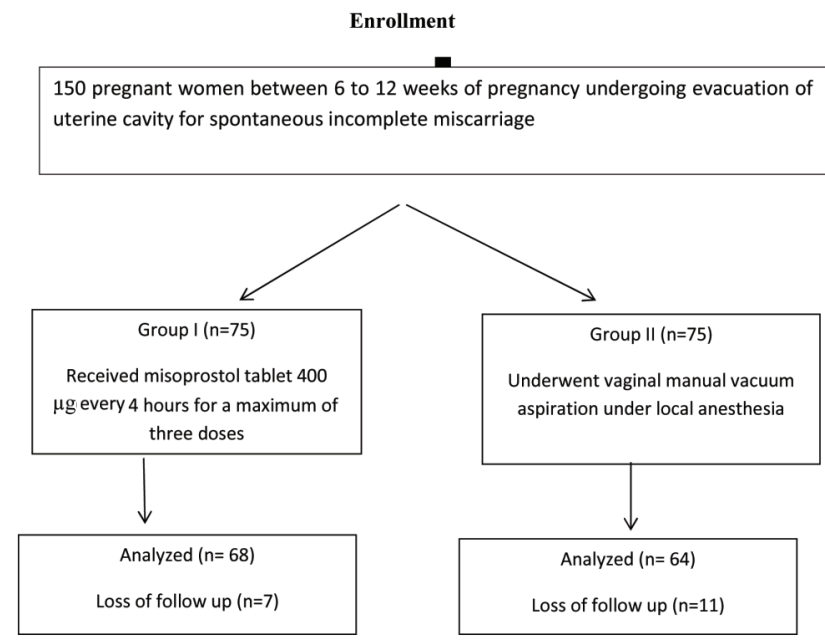

Fig 1. A flowchart of study procedure including patient enrollment, allocation, follow up and analysis

\section{RESULTS}

Table 1 shows characteristics of the study population at enrollment of two groups with statistically non significant difference ( $p>0.05$ ). Table 2 shows clinical outcome of study groups. Success rate of MVA group was $100 \%$ and for misoprostol group, it was $67.7 \%$ with statistically significant difference $(p<0.05)$. Incidence of excessive bleeding in MVA group was $3.13 \%$ while in misoprostol group was $14.7 \%$ (pvalue $=0.021$ ). In pain and bleeding, there were statistically significant differences in both groups $(\mathrm{p}<0.05)$. Most common side effect observed was retained products of conception (POC) $(n=22,43.13 \%)$ followed by bleeding $(n=10,19.61 \%)$, diarrhoea $(n=9,17.64 \%)$, fever $(n=4,7.84 \%)$, vomiting $(n=3$, $5.88 \%)$ and shivering $(n=2,3.92 \%)$ and infection $(n=1$, $1.96 \%$ ) (figure 2)

\section{Table 1. Characteristics of the study population}

\begin{tabular}{|c|c|c|c|c|c|}
\hline \multirow[t]{2}{*}{ Variables } & \multicolumn{2}{|c|}{$\begin{array}{l}\text { Misoprostol group } \\
(\mathrm{n}=68)\end{array}$} & \multicolumn{2}{|c|}{$\begin{array}{l}\text { MVA group } \\
(\mathrm{n}=64)\end{array}$} & \multirow[t]{2}{*}{$\begin{array}{l}\text { Chi square } \\
\text { (P-value) }\end{array}$} \\
\hline & No. & $\%$ & No. & $\%$ & \\
\hline Primiparous & 14 & 20.6 & 16 & 25 & 0.546 \\
\hline Multiparous & 54 & 79.4 & 48 & 75 & 0.546 \\
\hline First time abortion & 14 & 20.6 & 16 & 25 & 0.546 \\
\hline $\begin{array}{l}\text { Abortion after } \\
\text { previous } \mathrm{C} / \mathrm{S} \text {. }\end{array}$ & 10 & 14.7 & 8 & 12.5 & 0.712 \\
\hline $\begin{array}{l}\text { History of previous } \\
\text { one or more abortion }\end{array}$ & 14 & 20.6 & 12 & 18.6 & 0.791 \\
\hline $\begin{array}{l}\text { Abortion after normal } \\
\text { delivery. }\end{array}$ & 30 & 44.1 & 28 & 43.8 & 0.966 \\
\hline
\end{tabular}


Table 2. Clinical outcome of the study groups

\begin{tabular}{|l|l|l|l|l|l|}
\hline \multirow{2}{*}{ Clinical Outcomes } & \multicolumn{2}{|l|}{$\begin{array}{l}\text { Misoprostol group } \\
\text { Total no. 68 }\end{array}$} & \multicolumn{2}{|l|}{$\begin{array}{l}\text { MVA group under local } \\
\text { anesthesia. }\end{array}$} & $\begin{array}{l}\text { Chi square no. } 64 \\
\text { (p-value) }\end{array}$ \\
\cline { 2 - 6 } & No. & $\%$ & No. & $\%$ & \\
\hline $\begin{array}{l}\text { Success of the } \\
\text { treatment method }\end{array}$ & 46 & 67.7 & 64 & $100 \%$ & 0.001 \\
\hline $\begin{array}{l}\text { Incidence of excessive } \\
\text { bleeding during } \\
\text { procedure. }\end{array}$ & 10 & 14.7 & 2 & 3.13 & 0.021 \\
\hline
\end{tabular}

Figure 2. Frequency (\%) side effects of misoprostol in 68 patients under medical treatment

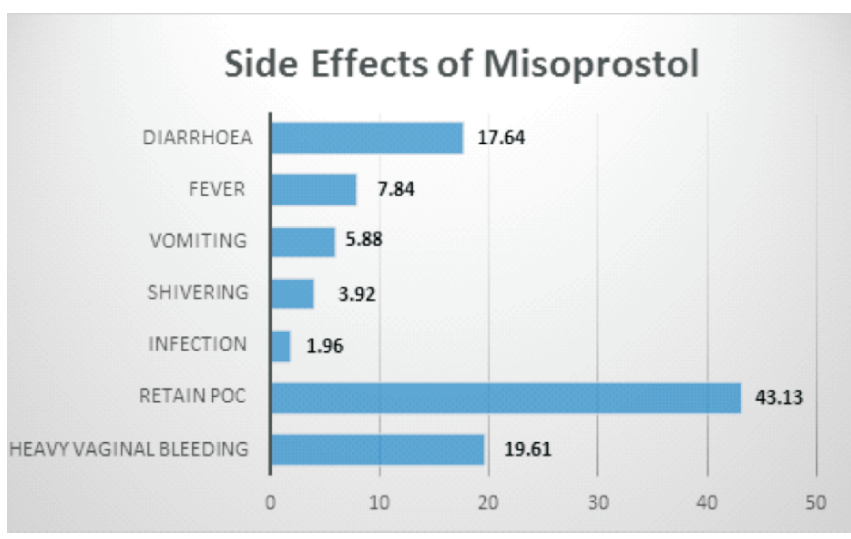

\section{DISCUSSION}

The current study compared the efficacy of sublingual misoprostol $400 \mu \mathrm{g}$ every 4 hourly for a maximum of three doses versus manual vacuum aspiration under local anesthesia of spontaneous first trimester incomplete miscarriage. Regarding the success rate, this study showed $400 \mu \mathrm{g}$ sublingual misoprostol was effective in $67.7 \%$ of spontaneous incomplete miscarriage whereas MVA under local anesthesia was successful in $100 \%$ of cases and there were statistically significant difference in success rate of both the procedures. Although, success rate of misoprostol in incomplete miscarriage have been reported from $87-97 \% .{ }^{7}$ Our results are almost similar with previous studies where MVA was found to be effective for women with incomplete miscarriage of uterine size of less than 12 weeks. ${ }^{3,4,5}$

About safety, present study demonstrates that women in misoprostol arm experienced more side effects than women in MVA group which was similar with other studies., Misoprostol have several side effects like heavy bleeding, infection, shivering, vomiting and fever. For surgical option, WHO has listed MVA as a safe, effective method for management of miscarriage. Present study has shown that in misoprostol group, there was excessive bleeding during the procedure and was observed statistically significant difference as compared to MVA counterpart ( $p$-value $=0.021$ ). This study was similar to Davis et al, where bleeding was found to be less in MVA group ${ }^{8}$ but was in contrast to Shwekerela et al, ${ }^{9}$ who reported pain and bleeding as statistically significant difference in side effect in MVA group than in misoprostol group.

This study reported that retained POC, vaginal bleeding and diarrhea are common side effects of misoprostol. Fever is less common and an antipyretic can be used for its relief. ${ }^{10}$ Nausea, vomiting and chills may occur but resolves 2 to 6 hours after taking misoprostol. An anti-emetic can be used if needed. ${ }^{10}$ All side effects were mild and managed easily. In our study, there was some loss of follow-up in both groups. According to some previous study, high rate of loss of follow-up are common with incomplete abortion treatment, particularly where cost and distance to care are substantial factors, as well as in settings where abortion is illegal. ${ }^{11,12}$ Telephone follow-up could also be established to reduce the need for in-person assessment. ${ }^{13}$

In present study, MVA is more effective and safer than misoprostol for treatment of incomplete miscarriage of uterine size of less than 12 weeks.

\section{CONCLUSION}

This study showed that MVA under local anesthesia is effective than sublingual misoprostol in the treatment of spontaneous incomplete miscarriage. However misoprostol is effective and safe alternative to the MVA under local anesthesia especially when surgical management is not available or risky or patient refused to undergo surgical management.

\section{REFERENCES}

1. Tasnim N, Mahmud G, Fatima S, Sultana M. Manualvacuum aspiration: a safe and cost effective substituteof Electric vacuum aspiration for the surgicalmanagement of early pregnancy loss. J Pak Med Assoc. 2011: 61;149-53.

2. Steer C, Campbell S, Davies M, Mason B, Collins WP. Spontaneous abortion rates after natural and assisted conception. BMJ 1989;299:13178

3. Blum J, Winikoff B, Gemzell-Danielsson K. Treatment of incomplete abortion and miscarriage with misoprostol. Int $\mathrm{J}$ of Gynae and Obstet 2007; 799, S186S189

4. Talemoh D, Akinsewa A, Paschal A et al. Introducing misoprostol for the treatment of incomplete abortion in Nigeria. Afr J Reprod Health 2011; 15(4): 42-50. 
5. Rasch V. Unsafe abortion and postabortion carean overview. Acta ObstetGynecolScand 2011:90:6927

6. Allen RH, Fitzmaurice G, Lifford KL. Oral compared with intravenous sedation for first-trimester surgical abortion. Obstet Gynecol. 2009;113(6):27683) 00.

7. Grimes DA, Benson J, Singh S, Romero M, Ganatra B, Okonofua FE, Shah IH. Unsafe abortion: the preventable pandemic. The Lancet. 2006;368:1908-19)

8. Davis A, Westhoff C, De Nonno L. J Am Med WomensAssoc (1972). 2000;55(3 Suppl):141-4

9. Shwekerela B, Kalumuna R, Kipingili R, Mashaka N, Westheimer E, Clark W, et al. Misoprostol for Treatment of Incomplete Abortion at the Regional Hospital Level: Results from Tanzania. BJOG 2007;114(11):13637

10. Tang OS, Gemzell-Danielsson K, Ho PC. Misoprostol: pharmacokinetics profiles, effects on the uterus andside-effects. Int J GynecolObstet2007;99 (Suppl2): S1607.)
11. Bique C, Ustá M, Debora B, Chong E, Westheimer E, Winikoff $\mathrm{B}$ : Comparison of misoprostol and manual vacuum aspiration for the treatment of incomplete abortion. Int J Gynaecol Obstet. 2007, 98 (3): 222-226. 10.1016/j.ijgo.2007.05.003

12. Weeks A, Alia G, Blum J, Winikoff B, Ekwaru P, Durocher J, Mirembe F: A randomized trial of misoprostol compared with manual vacuum aspiration for incomplete abortion. Obstet Gynecol. 2005,106 (3): 540-547.10.1097/01.AOG.0000173799 .82687.dc.

13. Grossman D, Ellertson C, Grimes DA, Walker D: Routine follow-up visits after first-trimester induced abortion. Obstet Gynecol. 2004, 103 (4): 738-745. 10.1097/01.AOG. 0000 115511.14004 